\title{
The Impact of Rusnani Concept Mapping (RCM) on Academic Achievement and Clinical Practices among Diploma Nursing Students
}

Submitted: 4-5-2017

Accepted: 21-7-2017

Online: 29-12-2017

\author{
Rusnani Ab Latif', Akehsan Dahlan², Zamzaliza Abdul Mulud², \\ Mohd Zarawi Mat Nor ${ }^{3}$ \\ ${ }^{1}$ Kubang Kerian Nursing College, Kelantan, MALAYSIA \\ ${ }^{2}$ Faculty of Health Sciences, Universiti Teknologi MARA, Puncak \\ Alam, Selangor, MALAYSIA \\ ${ }^{3}$ School of Medical Sciences, Universiti Sains Malaysia, Kelantan, \\ MALAYSIA
}

To cite this article: Ab Latif R, Dahlan A, Abdul Mulud Z, Mat Nor MZ. The impact of Rusnani Concept Mapping (RCM) on academic achievement and clinical practices among diploma nursing students. Education in Medicine Journal. 2017;9(4):1-12. https://doi.org/10.21315/eimj2017.9.4.1

To link to this article: https://doi.org/10.21315/eimj2017.9.4.1

\section{ABSTRACT}

Introduction: In Malaysian nursing education, concept mapping is not widely practiced among nurse educators and students. Therefore, the researcher aims to develop and evaluate the impact of the Rusnani Concept Mapping (RCM) protocol on academic achievement and clinical practices among diploma nursing students. RCM is one of the teaching learning methods that specifies guidelines for nurse educators to harmonise classroom and clinical setting methods. Method: RCM is a concept mapping protocol guideline developed by the researcher and is validated with content and face validity and the Delphi technique. The study design is quasi-experimental with two groups. The experimental and control groups received education using RCM and the lecture method, respectively. Data were analysed using descriptive and inferential statistics using paired $t$-tests. $P$ values less than 0.05 were interpreted as significant. Results: In the pre-test, the students taught using RCM had a mean achievement score of 11.23 with and $S D=2.59$, while at post-test, the mean achievement score was 13.19 with and $\mathrm{SD}=1.71$ and a mean gain score of 1.96 . In contrast, students taught using lecture method had a mean achievement score of 10.71 and $\mathrm{SD}=2.23$ in the pre-test and a mean score of $12.60, \mathrm{SD}=1.64$ in post-test achievement with a mean gain score of 1.89 . The post-test scores of the experimental and control group were significantly different $(t=2.53, p<0.05)$. The mean concept mapping care plan score was 59.33 and 65.23, respectively, for the control group and experimental group. The paired $t$-test revealed that there was a significant difference between experimental and control groups, $p$ value $<0.05$. The result of students' perceptions regarding concept mapping in the experimental group showed as positive moderate with a mean score of 3.44. Conclusion: This study provides additional evidence that RCM is instructionally valuable as a learning method and is an active learning strategy for meaningful learning and motivating superior achievement in students.

Keywords: Rusnani Concept Mapping (RCM), Academic achievement, Clinical practices, Nursing students 


\section{INTRODUCTION}

Excellence in academic and practical skills is the main goal of most nursing educators and is also used to measure success levels in teaching. Therefore, it is the responsibility of the educator to choose the teaching method that makes learning meaningful and effective for the students' cognitive structure and that will help the student to understand the topic being taught. However, students should take responsibility for their own learning. Concept mapping is one example of critical thinking improvement, because during the construction of maps, students draw the content map, thus allowing for the use of cognitive skills, such as analysis, evaluation and reasoning (1). Concept mapping, as a student-directed strategy, promotes the use of self-monitoring, increases self-efficacy, and leads to better student achievement (2). The use of concept mapping makes students better understand the relationship between patient data and the disease process and provides students with the 'big picture' for patient care (3).

However, because there is scant research on the use of concept mapping in the context of Malaysian nursing education, concept mapping is not widely practiced among nurse educators and students. Therefore, the researcher aims to develop and evaluate the impact of the Rusnani Concept Mapping (RCM) protocol on critical thinking skills and clinical practices among diploma nursing students. RCM is one of the teaching learning methods that specifies guidelines for nurse educators to harmonise classroom and clinical setting methods. In an effort to prepare nursing students to provide safe quality care, critical thinking skills have become essential to nursing education. If nurse educators do not, to some degree, begin using alternative and more interactive classroom activities, opportunities for critical thinking will be limited.

\section{RESEARCH OBJECTIVES}

1. To determine the effectiveness of RCM as a teaching method for the academic achievement of diploma nursing students' pre- and post-test.

2. To determine the effectiveness of a concept mapping care plan on the academic performance of diploma nursing students during clinical practice.

3. To identify the perceptions of students in the experimental group with respect to using RCM as a learning tool.

\section{LITERATURE REVIEW}

Concept mapping was originally developed by Novak in the 1980s to document the way children learn science (4). As an alternative to the traditional lecture, concept mapping is an instructional strategy to visually represent and organise knowledge and to facilitate the process of meaningful learning (5). In addition to aiding in the representation and development of meaningful learning, concept mapping is considered to be predictive of critical thinking $(6,7,8,9,10)$. A concept map also helps the nurse see the relationships between certain assessment findings and allows for addressing such related findings with the same interventions. The above assertion incorporates the concepts of critical thinking, life-long adult learning and the professional mandates that nurses will practice. Through concept mapping, students should be able to transfer applied didactic objectives from the classroom to clinical practice, where critical thinking and problem-solving skills are needed for success. Available data suggest that newly graduated nurses may lack knowledge about the development of the critical and reflective-thinking skills that are necessary for safe and effective clinical reasoning (11). Therefore, nurse educators need to examine their assumptions regarding curriculum and traditional teaching methods. 
Similarly, Li-Ling (12) aptly developed her research questions by examining the possibility of establishing high-quality nursing education when nursing faculty treat their work as mere routine and do not change their clinical teaching methods. It is important that nurse educators also play a role as researchers to investigate the didactic validity of teaching and assessment methods on a continuous basis and to specify guidelines to improve the practices of educators for promoting the critical thinking skills of student nurses. Nursing students struggle with the concept of the nursing process and its application to clinical practice; those students who lack understanding in their learning use rote memorisation.

\section{METHODS}

\section{Validation and Reliability of RCM}

Development of the RCM protocol guidelines is based on the Mohd Afifi Learning Model (MoAFF), ADDIE Model and integrated with the Kemp model (see Figure 1). This model has five phases: analysis, design, development, implementation and evaluation. The validity of the protocol was determined by using content and face validity. Content validity for this lesson plan was established using expert review and involved seven expert panels using both content and face validity. Meanwhile, the Delphi technique was used to validate the concept mapping care plan

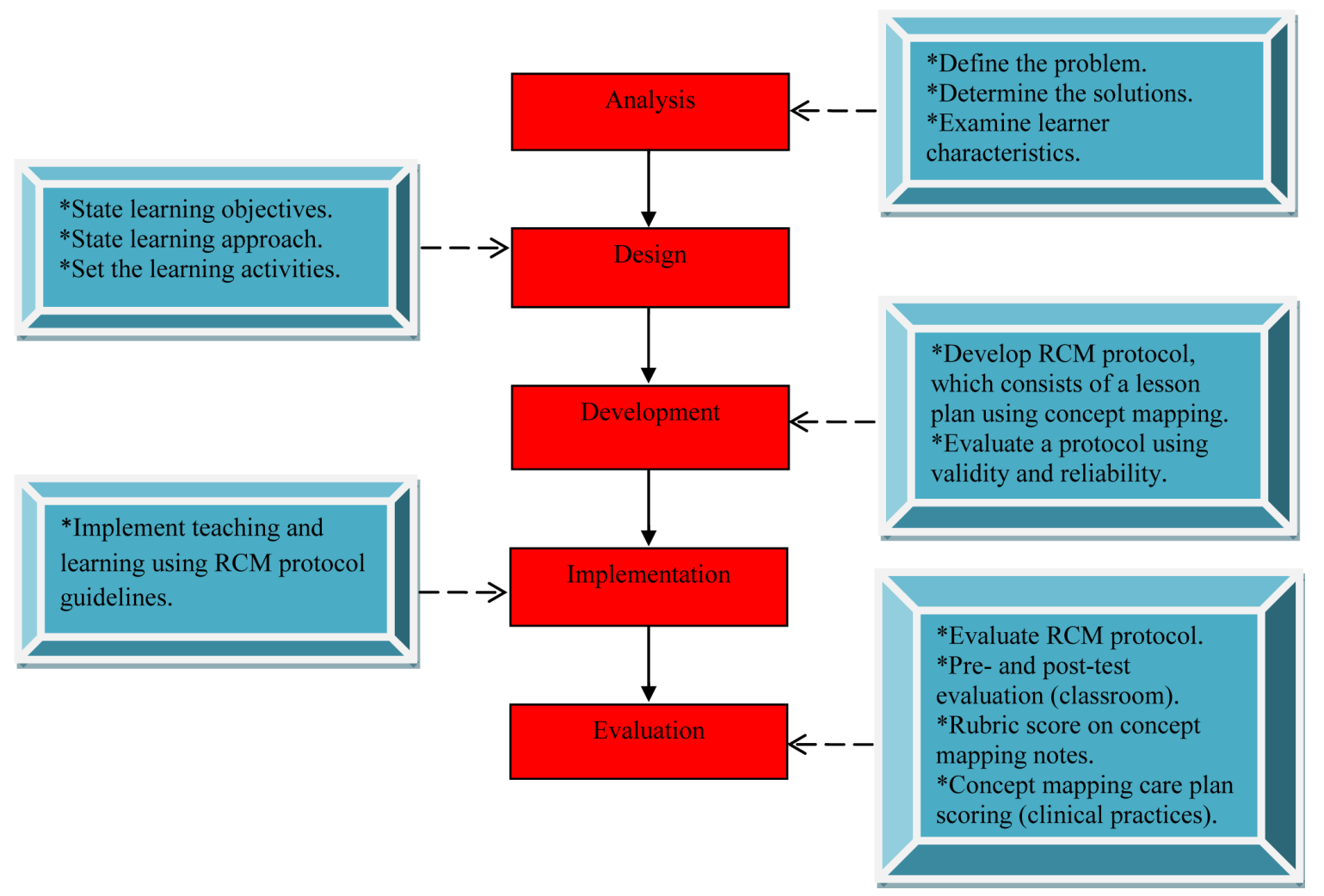

Sign:

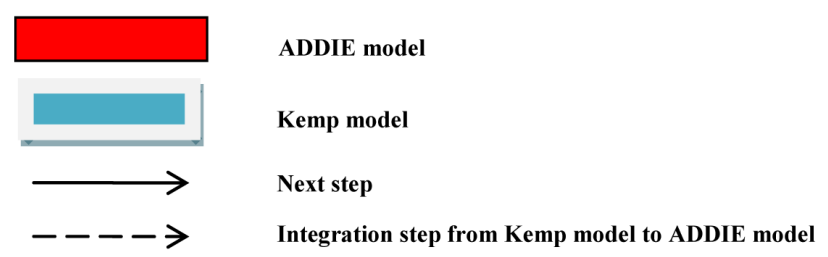

Figure 1: Rusnani Concept Mapping (RCM) protocol guidelines, adaptation from Mohd Afifi Learning Model (MoAFF). 
and multiple-choice questions (MCQ). There were ten expert panels involved in validating the concept mapping care plan and MCQ. The reliability of the protocol was 0.816 , indicating that the RCM protocol has high reliability and validity.

\section{Research Design and Population}

This study was carried out based on the random selection of 17 nursing colleges under the Institusi Latihan Kementerian Kesihatan Malaysia (ILKKM) in Malaysia. The study design was quasi-experimental with two groups and pre- and post-test. Multi-stage sampling was used to select a representative sample for the study from four nursing colleges that were selected as the study population based on zones. The colleges were selected by zone: the East zone includes Kolej Kejururawatan Kubang Kerian (KKKK), Kelantan; the Northern zone includes Kolej Kejururawatan Pulau Pinang (KKPP), Penang; the Central zone includes Kolej Sains Kesihatan Bersekutu (KSKB) Sungai Buluh; and the Southern zone includes Kolej Kejururawatan Melaka (KJM). Based on the random sample, students were selected and assigned to the control (KSKB Sungai Buluh and KJM) or experimental group (KKKK and KKPP).

\section{Sample Size}

Sample size from Krejcie \& Morgan (13) was used with a confidence level of $95 \%$; thus, the sample size required was 218 respondents. Respondents were randomly divided into two groups. One group was considered the experimental group (RCM) and had 109 participants; the other group was considered the control group (lecture method) and had 109 participants.

\section{Data Collection}

The multiple-choice question (MCQ) test was used as both pre- and post-test and has 20 questions on the topic of diabetes mellitus and four optional multiple choice questions. There were three rounds of the
Delphi technique in seeking a consensus of concept mapping care plan and MCQ in the diabetes mellitus subject area. Ten expert panels were involved in evaluating the concept mapping consensus. Participants were asked to rate the categorised responses from Round 1 on a scale of 1 to 5 , with 1 being "Very Irrelevant" and 5 being "Very Relevant". The pre- and post-test scores (didactic theory) and concept mapping structure (clinical practices) were given to both groups. The concept mapping structure was a score based on three categories adapted from Ainsley (14): [<33.3\%: Low; $>33.3-66.6 \%$ : Moderate; and $>66.6 \%$ : High]. Only the experimental group was given the questionnaire on perceptions about concept mapping that comprised 10 items; adapted from Chiou (15). Statistical Package for the Social Sciences for Windows (SPSS) Version 23 software was used to analyse the data. Descriptive values of items were expressed as the mean, standard deviation, frequency and per cent, after ensuring normal distribution of the variables (Kolmogorov-Smirnov test). The paired $t$-test was performed to compare the mean difference in pre- and post-test scores between experimental and control groups. The paired $t$-test was also used to compare concept mapping structure during clinical practice between the experimental and control groups. $P$ values less than 0.05 were interpreted as significant.

\section{Study Ethics}

Ethical approval was obtained from the Medical Research Ethics Committee of Faculty Medicine and Health Sciences, UiTM, Puncak Alam. Before carrying out this research project, an approval letter was sent to Bahagian Pengurusan Latihan (BPL) and the four Directors of Nursing Colleges ILKKM for consent. The researcher explained the study aims and procedures to the respondents and also explained that their answers were confidential and would only be used for the purpose of academic research. Written informed consent was obtained from all participants. 


\section{RESULTS}

\section{Socio Demographic Characteristics of the Nursing Students}

A total of 218 respondents participated in this study, leading to a response rate of $100 \%$. The mean respondent age was $22.14(\mathrm{SD}=1.48) ; 151$ respondents were aged 19 to 22 years $(69.3 \%)$, and 67 respondents were aged 23 to 26 years $(30.7 \%)$. The modal student age was 21 years $(96 ; 44.0 \%)$. The majority of study respondents were Malay $(211 ; 96.8 \%)$, followed by Indian $(7 ; 3.2 \%)$. The religion of most respondents was Islam $(211 ; 96.8 \%)$, followed by Hindu $(5 ; 2.3 \%)$, and Christian (2; $0.9 \%)$. The educational level of most respondents was Sijil Pelajaran Malaysia (SPM) level (135; 61.9\%), followed by diploma or degree $(58,26.6 \%)$, and Sijil Tinggi Persekolahan Malaysia (STPM) (25, $11.5 \%)$. Regarding interest in nursing, 203 $(93.1 \%)$ respondents indicated an interest in nursing, and $15(6.9 \%)$ were not interested in nursing. Mean grade point average (GPA) was $3.26(\mathrm{SD}=0.22)$. Respondents' grades were as follows: $101(46.3 \%)$ received a grade of $\mathrm{B}(3.00), 79(36.2 \%)$ a grade of $\mathrm{B}+$ (3.33), $29(13.3 \%)$ a grade of B- (2.67), and $9(4.1 \%)$ a grade of $A-(3.67)$.

\section{Descriptive Statistics on Academic Performance of Nursing Students during Didactic Theory}

Table 1 shows the mean pre- and post-test achievement score and standard deviation of students for the MCQ by teaching strategy. The table shows the effect of teaching strategies, RCM and lecture, on mean student achievement score in the medical subject area of diabetes mellitus. The data in Table 2 indicate that at pre-test, the students taught using RCM had a mean achievement score of 11.23 with a standard deviation of 2.59 , while at post-test, the mean achievement score was 13.19, the standard deviation was 1.71 , and the mean gain score was 1.96. In contrast, at pre-test, students taught using the lecture method had a mean achievement score of 10.71 with a standard deviation of 2.23, while at post-test, the mean achievement score was 12.60 , the standard deviation was 1.64 , and the mean gain score was 1.89 . These results indicate that the experimental group appears to have performed better than the control group in the achievement test and indicate an increase in mean post-test score.

\section{Inferential Statistics on the Academic Achievement of Nursing Students during Didactic Theory}

Table 2 shows that no significant difference was observed in mean pre-test academic achievement score between the experimental and control groups $(t=1.67, p>0.05)$. This result implies that at pre-test, students in both groups had the same level of academic achievement in diabetes mellitus subject courses. However, post-test score results showed a significant difference $(t=2.53$, $p<0.05)$ between the experimental and control groups, demonstrating that the experimental group out-performed the control group. Thus, there is strong evidence that teaching with RCM improves academic achievement scores. This outcome shows that students taught through RCM had higher mean academic achievement scores

Table 1: Mean student MCQ pre- and post-test achievement score and standard deviation by teaching strategy $(n=218)$

\begin{tabular}{|c|c|c|c|c|c|c|}
\hline \multirow{2}{*}{ Teaching strategy } & \multirow{2}{*}{$\mathbf{N}$} & \multicolumn{2}{|c|}{ Pre-test } & \multicolumn{2}{|c|}{ Post-test } & \multirow{2}{*}{ Mean gain } \\
\hline & & Mean & SD & Mean & SD & \\
\hline $\begin{array}{l}\text { Rusnani Concept Mapping } \\
\text { (Experimental group) }\end{array}$ & 109 & 11.23 & 2.59 & 13.19 & 1.71 & 1.96 \\
\hline Lecture (Control group) & 109 & 10.71 & 2.23 & 12.60 & 1.64 & 1.89 \\
\hline
\end{tabular}


Table 2: Comparison of mean academic achievement post-test scores by experimental and control group $(n=218)$

\begin{tabular}{rlcccccc}
\hline Test & \multicolumn{1}{c}{ Group } & $\mathbf{N}$ & Mean & SD & df & $\boldsymbol{t}$-value & $\boldsymbol{p}$-value \\
\hline Pre-test & Experimental & 109 & 11.23 & 2.59 & 108 & 1.67 & 0.098 \\
& Control & 109 & 10.71 & 2.23 & & & \\
\multirow{2}{*}{ Post-test } & Experimental & 109 & 13.19 & 1.71 & 108 & 2.53 & $0.013^{*}$ \\
& Control & 109 & 12.60 & 1.64 & & & \\
\hline \multicolumn{7}{c}{$p<0.05$ significant }
\end{tabular}

and performed better than students taught through the lecture method. Hence, the alternative hypothesis, 'There is a significant difference in mean gain score between students taught through RCM and lecture method', was accepted. These results show that on the MCQ test, students who were taught through RCM had achievement score gains and performed better than students taught by lecture method.

\section{Descriptive Statistics on the Academic Performance of Nursing Students during Clinical Practice}

Table 3 shows respondents' data divided into three groups of scores by student grade level: Low (< 33.3), Moderate ( $>$ 33.3$66.6 \%$ ) and High (> 66.6\%). Compared to the control group, where only 37 students $(17.0 \%)$ received a High score grade, in the experimental group, 52 students (23.9\%) received a High score grade. However, the control group had a greater percentage of students who received a Moderate score grade $(\mathrm{n}=72,33.0 \%)$ than the experimental group $(\mathrm{n}=57,26.1 \%)$. No respondent in either group received a Low score grade.

\section{Inferential Statistics on the Academic Performance of Nursing Students during Clinical Practice}

Table 4 indicates that compared to the lecture method (control group), students taught through RCM (experimental group) had a higher mean gain score in concept mapping structure at clinical practice. Descriptive statistical analysis was used to compare the mean of the two groups on for the concept mapping care plan during

Table 3: Distribution of concept mapping care plan score at clinical practice by experimental and control group $(n=218)$

\begin{tabular}{|c|c|c|c|c|}
\hline \multirow{2}{*}{ Score } & \multicolumn{2}{|c|}{ Experimental group } & \multicolumn{2}{|c|}{ Control group } \\
\hline & $\mathrm{n}$ & $\%$ & $\mathrm{n}$ & $\%$ \\
\hline Low $(<33.3 \%)$ & - & - & - & - \\
\hline Moderate (> 33.3-66.6\%) & 57 & 52.3 & 72 & 66.1 \\
\hline High (> 66.6\%) & 52 & 47.7 & 37 & 33.9 \\
\hline
\end{tabular}

Table 4: Comparison of mean concept mapping care plan scores during clinical practice by experimental and control group $(\mathrm{n}=218)$

\begin{tabular}{clcccccc}
\hline Test & \multicolumn{1}{c}{ Group } & N & Mean & SD & df & t-value & $\boldsymbol{p}$-value \\
\hline Concept mapping plan & Experimental & 109 & 65.24 & 9.28 & 108 & 4.54 & $0.01^{*}$ \\
& Control & 109 & 59.34 & 11.26 & & & \\
\hline & \multicolumn{7}{c}{$p<0.05$ significant }
\end{tabular}


clinical practice, which was $65.24, \mathrm{SD}=$ 9.28 and 59.33, SD $=11.26$, respectively, for the experimental and control groups.

The paired $t$-test revealed that there was a significant between group difference; $t$ (4.54, $108), p$ value $<0.05$. Thus, compared with the control group, experimental subjects had higher concept mapping care plan scores. Hence, the alternative hypothesis stating, "There is a significant difference in mean academic performance gain score between diploma nursing students taught through RCM and lecture method during clinical practice", was accepted.

\section{Students' Perceptions towards Concept Mapping}

Perceptions of the experimental group regarding concept mapping were adapted from Chiou (15). Table 5 shows the perceptions of the experimental group regarding concept mapping. The responses to the satisfaction for each item were collapsed into "agree" (answers of "strongly agree" or "agree") or "disagree" (answers of "strongly disagree" or "disagree") and were converted into frequencies. Questions 1-4 investigated whether the concept mapping strategy indeed improved learning. The data in Table 9 show that $100 \%$ of the students agreed that concept mapping helped them learn nursing subjects and integrate and clarify the inter-relationships among curriculum content and that concept mapping stimulated them to learn and think independently. The majority of students (96\%) expressed the opinion that concept mapping helped reduce barriers and enhance their interest in learning subjects in Nursing.

Questions 5-10 are related to the degree of the affective acceptance of the concept mapping group. Ninety-eight percent of the students deemed that concept mapping can be a new teaching and learning approach in Nursing and would consider using the concept mapping learning strategy in other curricula. Meanwhile, $99 \%$ of the students thought that the concept mapping strategy

Table 5: Summary of experimental class perceptions towards concept mapping $(n=109)$

\begin{tabular}{|c|c|c|c|c|}
\hline & Items & $\%$ & Mean & SD \\
\hline 1 & Concept mapping helped me learn subjects in Nursing & 100 & 3.51 & .502 \\
\hline 2 & $\begin{array}{l}\text { Concept mapping helped me integrate and clarify the } \\
\text { interrelationships among curriculum contents }\end{array}$ & 100 & 3.44 & .499 \\
\hline 3 & $\begin{array}{l}\text { Concept mapping learning strategy stimulated me to learn and } \\
\text { think independently }\end{array}$ & 100 & 3.40 & .493 \\
\hline 4 & $\begin{array}{l}\text { Concept mapping helped me reduce barriers and enhance my } \\
\text { interest in learning subjects in Nursing }\end{array}$ & 96 & 3.36 & .553 \\
\hline 5 & $\begin{array}{l}\text { Concept mapping can be a new teaching and learning approach } \\
\text { in Nursing }\end{array}$ & 98 & 3.48 & .537 \\
\hline 6 & $\begin{array}{l}\text { I think the concept mapping strategy can be easily used in other } \\
\text { curricula }\end{array}$ & 99 & 3.44 & .517 \\
\hline 7 & $\begin{array}{l}\text { I will consider using the concept mapping learning strategy in } \\
\text { other curricula }\end{array}$ & 98 & 3.39 & .525 \\
\hline 8 & $\begin{array}{l}\text { I was satisfied with using concept mapping to learn subjects in } \\
\text { Nursing }\end{array}$ & 99 & 3.50 & .520 \\
\hline 9 & $\begin{array}{l}\text { I liked using concept mapping to assist me to learn subjects in } \\
\text { Nursing }\end{array}$ & 100 & 3.48 & .554 \\
\hline 10 & I can soon adapt to concept mapping & 99 & 3.42 & .496 \\
\hline Total & & & 3.44 & \\
\hline
\end{tabular}


could be easily used in other curricula, were satisfied with using concept mapping to learn subjects in Nursing and could adapt to concept mapping. However, $100 \%$ of students liked using concept mapping to assist in learning subjects in Nursing. The results indicated that most of the students gave positive feedback after learning and applied concept mapping in their learning. According to Abdul Ghaffar (16), researchers can use a variety of theories and formulate their own index based on the objectives of the study. Thus, to classify the mean value of low, medium and high scores, the researcher used the mean score (see Table 6).

Table 6: Analysis of Likert scale (mean score)

\begin{tabular}{cc}
\hline Mean score & The level of agreement \\
\hline $0.00-1.50$ & Very low \\
$1.51-2.50$ & Low \\
$2.51-3.50$ & Moderate \\
$3.51-4.50$ & High \\
$4.51-5.00$ & Very high \\
\hline
\end{tabular}

\section{DISCUSSION}

\section{The Effectiveness of RCM, as a Teaching Method, on the Academic Achievement of Diploma Nursing Students' Pre- and Post- Test Scores}

The findings of this study give further credence to Ezeudu (17), Ezeugo \& Agwagah (18), Imoko (19), Rahmani et al. (20) and Okonkwo (21), who reported that students exposed to concept mapping demonstrated more in-depth understanding of concepts than those exposed to the lecture method. Similar finding by Parsa \& Nikbakth (22) stated that concept mapping is better than the lecture method in producing meaningful learning. Concept mapping is a learning strategy for nursing education, and students found that concept mapping enhanced their understanding of concepts (23). Concept maps have been described as a powerful teaching and learning technique for nursing education that facilitate meaningful learning (24). The present research report by $\mathrm{McDaniel}$, Roth \& Miller (25) indicates that concept mapping activities improve students' academic success. The results of this study indicate that participants in both the experimental and control group scored similarly on the pre-test exam. However, a notable difference in group post-test gains was revealed. In contrast, findings from research conducted by Sarhangi et al. (26) reported that there was no significant difference between experimental and control groups in concept mapping and lecture method in learning effectiveness. Another study used a pre-post test design with control group to evaluate the effect of concept mapping on the critical thinking skills of nursing students (1). The results revealed that although this study did not find a significant difference between experimental and control groups, the withingroup results showed that concept mapping is effective in helping students develop critical thinking skills.

\section{The Effectiveness of Concept Mapping Care Plan on the Academic Performance of Diploma Nursing Students during Clinical Practice}

The results showed that students in the experimental group had a higher gains in concept mapping care plan score, performed better than students taught through the lecture method and that the use of concept mapping strategies significantly improved students' critical thinking skills, as determined by concept map care plan scores and academic achievement, as measured by post-test scores. In nursing education, concept mapping has been used as a teaching strategy to provide students the opportunity to visualise and integrate theories with the nursing process. Concept mapping of patient problems allowed students and instructors to see interrelationships in patient data, analyse patient data and plan comprehensive nursing care. Previous studies recommended 
that replacing traditional care plans or nursing care plans with concept mapped care plans helps students learn how patients' various problems are connected to one another $(27,28,29)$. Concept map care plans have been implemented in overseas hospitals; however, in Malaysia such plans have not yet been implemented. Therefore, the concept mapping structure may be the best method for replacing current nursing care plans. Study results from Pickens (30), which included 54 junior baccalaureate nursing students, showed significant correlations among the concept mapping and synthesizer activities and unit exams in three of the eight activities. The literature review, however, revealed no empirical studies that used concept mapping in diploma nursing programmes to foster academic achievement or improve critical thinking abilities.

\section{Perceptions of Experimental Group Students towards Using RCM as a Learning Tool}

Perceptions of students on the use of RCM acceptance showed that students gave a positive moderate score with mean 3.44. This finding was similar to Aziz \& Jair (31) and was based on the students' acceptance of concept maps as positive-medium with mean score of 3.55. The results showed that the students agreed that using concept mapping was easier for remembering study content, an interesting teaching method and was not boring. Positive attitude, such as interested and committed, was shown by students during preparation of the concept maps. This finding was similar to Abdullah (32) and Jamrin (33), which showed that the students' acceptance towards concept maps was positive-medium. Positive-medium score means that not all students showed interest and were committed during concept map preparation.

Results for perceptions of RCM by the experimental group showed, overall, that the experimental group was more positive about the usefulness of concept mapping in enhancing learning effectiveness after it was applied. All respondents agreed that concept mapping is a learning strategy that stimulated the students to learn independently. This finding is similar to the study findings of Nirmala \& Shakuntala (34), Ahlberg et al. (35), Harpaz et al. (10), Novak et al. (36), and Novak \& Gowin (37). Furthermore, most students noted that adopting the concept mapping strategy helped them reduce barriers and promote their interest in learning nursing subjects. In terms of affective acceptance, the experimental group had a more affirmative attitude for using the concept mapping strategy. The overwhelming majority of students was of the opinion that concept mapping can be a potential accounting instructional strategy. Most of the students liked, and felt satisfied with, adopting concept mapping as an assistive learning strategy. The students in the concept mapping group also believed that concept mapping could be easily applied to other subjects. These opinions are consistent with successful examples of concept mapping use in other disciplines, such as Ahlberg et al. (35), Chang et al. (38), Freeman \& Jessup (39), Harpaz et al. (10), and Ritchie \& Volkl (40). Additionally, the majority of students indicated that they could adapt to the concept mapping approach. Moreover, concept mapping notes developed by students indicated students' understanding of the subject and helped students to summarise and synthesise the subject already taught. Concept mapping also plays a pivotal role in enhancing student-centred learning.

\section{Scope and Limitations of The Study}

The scope of the study was to conduct an assessment in training programmes on the teaching of the medical subject of diabetes mellitus using RCM protocol guidelines. However, there is no guarantee that the four individual teachers were similar in their teaching and assessment skills. Additionally, due to time constraints, the study was only carried out on specific topics. To ensure 
teaching and learning, in teaching the medical subject of diabetes mellitus for the experimental group that used concept mapping, the researcher has created a lesson plan that is similar in design and concept mapping and was given to the experimental nurse educator group. Another limitation of this study is the small sample size, which consisted of 218 Diploma Nursing student respondents that were selected from four zones (North, South, West and Central). Consequently, the results of this study cannot be generalised to all nursing students at ILKKM, which has 17 nursing colleges, and also may not be generalisable to the entirety of Diploma Nursing students under ILKKM.

\section{CONCLUSION}

The researcher believes that nursing curricula need to change to a studentcentred learning approach where students understand concepts, as opposed to the rote memorisation of facts. RCM teaching and learning methods can provide good learning effects and are able to stimulate the minds of students towards critical thinking. Therefore, the choice of appropriate teaching and strategies methods is important for providing learning effectiveness. Additionally, the majority of students indicated that they could adapt to the concept mapping approach. All respondents agreed that concept mapping is a learning strategy that stimulated students to learn independently. Therefore, nursing education should shift from lecture method to new educational strategies such as concept mapping to produce improvements in students' critical thinking. The researcher concluded that RCM is an effective learning strategy for helping nursing students apply what they learn in the classroom to clinical practice. This finding is in line with the vision and mission of ILKKM to produce nurses who are competent and knowledgeable.

\section{REFERENCES}

1. Wheeler LA, Collins SKR. The influence of concept mapping on critical thinking in baccalaureate nursing students. Journal of Professional Nursing. 2003;19(6):339-46. https://doi.org/10.1016/S8755-7223(03) 00134-0.

2. Chulart P, DeBacker T. The influence of concept mapping on achievement, selfregulation and self-efficacy in students of English as a second language. Contemporary Educational Psychology. 2004;29(3):248-63. https://doi.org/10.1016/j.cedpsych.2003. 09.001 .

3. Hsu L. Developing concept maps from problem-based learning scenario discussions. Journal of Advanced Nursing. 2004;48(5):510-18. https://doi.org/10.1111/ j.1365-2648.2004.03233.x.

4. Novak JD, Canas AJ. The theory underlying concept maps and how to construct and use them. Pensacola: Florida Institute for Human and Machine Cognition; 2006 [cited 2016 June 17]. Available from: https://cmap. ihmc.us/docs/theory-of-concept-maps.

5. Novak JD. Concept mapping: a useful tool for science education. JRST. 1990;27:93749. https://doi.org/10.1002/tea.3660271003.

6. Kinchin I, Hay D. Using concept maps to optimize the composition of collaborative student groups: a pilot study. Journal of Advanced Nursing. 2005;51(2):182-7. https://doi.org/10.1111/j.1365-2648.2005. 03478.x.

7. Roop KM. Effect of concept mapping as a learning strategy on certificate practical nursing students' academic achievement and critical thinking development [dissertation]. 2002. Available from: ProQuest Dissertations and Theses database (UMI No. 3047529). 
8. Wilgis $\mathrm{M}, \mathrm{McC}$ Connell $\mathrm{J}$. Concept mapping: an educational strategy to improve graduate nurses' critical thinking skills during a hospital orientation program. The Journal of Continuing Education in Nursing. 2008;39(3):119-26. https://doi. org/10.3928/00220124-20080301-12.

9. Facione N, Noreen P. Externalizing the critical thinking in knowledge development and clinical judgment. Journal of Nursing Outlook. 1996;45(6):129-136. https://doi. org/10.1016/S0029-6554(06)80005-9.

10. Harpaz I, Balik C, Ehrenfeld M. Concept mapping: an educational strategy for advancing nursing education. Journal of Nursing Forum. 2004;39(2):27-36. https:// doi.org/10.1111/j.0029-6473.2004.00027.x.

11. Fero L, Witsberger C, Wesmiller S, Zullo T, Hoffman L. Critical thinking ability of newgraduate and experienced nurses. Journal of Advanced Nursing. 2009;65(1):139-48. https://doi.org/10.1111/ j.1365-2648.2008.04834.x.

12. Li-Ling $\mathrm{H}$. An analysis of clinical teacher behavior in a nursing practicum in Taiwan. Journal of Clinical Nursing. 2006;15(5):619-28. https://doi.org/10.1111/ j.1365-2702.2006.01332.x.

13. Krejcie RV, Morgan DW. Small-sample techniques. The NEA Research Bulletin. 1960;38:99.

14. Ainsley J. CEO analysis: ten years of analysis of the course experience questionnaire surveys symposium 2003. Canberra; 2003

15. Chiou CC. The effect of concept mapping on students' learning achievements and interests. Innovations in Education and Teaching International. 2008;45(4):375-87. https://doi.org/10.1080/ 14703290802377240 .

16. Abdul Ghaffar MN. Reka bentuk tinjauan soal selidik pendidikan. Johor: Universiti Teknologi Malaysia; 2003.
17. Ezeudu FO. Effect of concept maps on students' achievement, interest and retention in selected units of organic chemistry [dissertation]. Nsukka: University of Nigeria; 1995.

18. Ezeugo NC, Agwagah UNV. Effect of concept mapping on students' achievement in algebra:implications for secondary mathematics education in the 21 st century. ABACUS. 2000;25(1):1-12.

19. Imoko BI. Effect of concept mapping on students' achievement and interest in trigonometry [dissertation].University of Nigeria, Nsukka; 2005.

20. Rahmani A, Mohajjel Aghdam A, Fathi Azar E, Abdullahzadeh F. Comparing the effect of concept mapping and integration method on nursing students learning in nursing process in Tabriz University of Medical Sciences. Iran Journal Medication Education. 2007;7:41-8.

21. Okonkwo IGA. Using concept mapping to teach separation of mixtures in SS 1. In: Ojokuku GO, Amadi EO, Mfon E, Udo U, Onwukwe EO. STAN chemistry panel workshop series 7; 2011; Zaria: Max Chin Multimedia. p. 79-82.

22. Parsa YZ, Nikbakth NA. Concept mapping as an educational strategy to promote meaningful learning. Journal Medical Education. 2004;5:47-50.

23. Hicks-Moore SL, Pastirik PJ. Evaluating critical thinking in clinical concept maps: a pilot study. International Journal of Nursing Education Scholarship. 2006;3(1). https:// doi.org/10.2202/1548-923X.1314.

24. Pilcher J. Teaching and learning with concept maps. Neonatal Network. 2011;30(5):336. https://doi.org/10.1891/0730-0832.30.5.336.

25. McDaniel E, Roth B, Miller M. Concept mapping as a tool for curriculum design. Issues in informing science and information technology [Internet]. 2005 [cited 2014 April 12]. Available from: http://proceedings. informingscience.org/InSITE2005/ I42f49McDa.pdf. 
26. Sarhangi F, Masumi M, Ebadi A, Seyyed Mazhari M Rahmani A. Comparing the effect of lecture and concept mapping based learning on cognitive learning. Iran Journal Critical Care Nursing. 2010;3:1-5.

27. Chabeli M. Concept-mapping as a teaching method to facilitate critical thinking in nursing education: a review of the literature. Health SA Gesondheid. 2010;15(1). https://doi.org/10.4102/hsag.v15i1.432.

28. Kostovich C, Poradzisz M, Wood K, O'Brien, K. Learning style preference and student aptitude for concept maps. Journal of Nursing Education. 2007;46(5):225-32.

29. Abel WM, Freeze M. Evaluation of concept mapping in an associate degree nursing program. Journal of Nursing Education. 2006;45(9):356-65.

30. Pickens CL. Concept mapping: methods to improve critical thinking. Journal of Continuing Education in Nursing. 2007;30(45).

31. Aziz Z, Jair N. Penggunaan peta konsep untuk meningkatkan pencapaian matapelajaran sejarah bagi pelajar tingkatan dua. Jurnal Pendidikan Malaysia. 2009;34(1):3-15.

32. Abdullah A. Keberkesanan penggunaan peta konsep dalam mata pelajaran Sains Tingkatan 1 [dissertation]. Universiti Kebangsaan Malaysia; 2000.

33. Jamrin MJ. Keberkesanan penggunaan teknik pengajaran peta konsep dalam mata pelajaran ekonomi asas tingkatan empat [dissertation]. Universiti Kebangsaan Malaysia; 2002.
34. Nirmala T, Shakuntala BS. Attitude of students on concept mapping- an innovative teaching learning strategy. Nitte University Journal of Health Sciences. 2012;2(4):39-43.

35. Ahlberg M, Aanismaa P, Dillon P. Education for sustainable living: Integrating theory, practice, design, and development. Scandinavian Journal of Educational Research. 2005;49(2):167-85. https://doi. org/10.1080/00313830500048923.

36. Novak JD, Gowin DB, Johansen GT. The use of concept mapping and knowledge via mapping with junior high school science students. Science Education. 1983;67(5):625-45. https://doi.org/10.1002/ sce. 3730670511 .

37. Novak JD, Gowin DB. Learning how to learn. New York: Cambridge University Press; 1984. https://doi.org/10.1017/ CBO9781139173469.

38. Chang KE, Sung YT, Chiou SK. Use of hierarchical hyper concept map in web-based courses. Journal of Educational Computing Research. 2002;27:335-53. https://doi.org/ 10.2190/MTUR-9BJQ-FE33-QM0A.

39. Freeman LA, Jessup LM. The power and benefits of concept mapping: measuring use, usefulness, ease of use, and satisfaction. International Journal of Science Education. 2004; 26(2):151-69. https://doi.org/10.1080/ 0950069032000097361 .

40. Ritchie D, Volkl C. Effectiveness two generative learning strategies in the science classroom. School Science and Mathematics. 2000;100(2):83-9. https://doi. org/10.1111/j.1949-8594.2000.tb17240.x. 